\title{
Study on the inhibition of inflammation by the cyclooxygenase-2 (COX-2)/prostaglandin E2 (PGE2) pathway and the promotion of wound healing of oral ulcer of Yangyin Shengji powder after chemotherapy
}

\author{
Yun Liu ${ }^{1}$, Sixiu Ren ${ }^{2}$, Hongjian Ji ${ }^{1}$, Daonan Yan $^{3}$ \\ ${ }^{1}$ Department of Otolaryngology, Wuxi Hospital Affiliated to Nanjing University of Chinese Medicine, Wuxi, China; ${ }^{2}$ Department of Traditional \\ Laryngology, Wuxi Hospital Affiliated to Nanjing University of Chinese Medicine, Wuxi, China; ${ }^{3}$ The First Clinical Medical College, Nanjing \\ University of Chinese Medicine, Nanjing, China \\ Contributions: (I) Conception and design: D Yan, Y Liu; (II) Administrative support: S Ren; (III) Provision of study materials or patients: D Yan, Y \\ Liu; (IV) Collection and assembly of data: Y Liu; (V) Data analysis and interpretation: H Ji; (VI) Manuscript writing: All authors; (VII) Final approval \\ of manuscript: All authors. \\ Correspondence to: Daonan Yan. The First Clinical Medical College, Nanjing University of Chinese Medicine, Nanjing210046, China. \\ Email: yandaon2006@163.com.
}

Background To investigate the treatment effect and mechanism of Yangyin Shengji powder in oral ulcer after chemotherapy.

Methods: The experiments were externally administered. The threshold of pain reflex (Tr) was measured 30, 60, and $120 \mathrm{~min}$ after the last relative substances administration to the plantar and abdomen of mice by intelligent hot plate instrument. The toe swelling degree of mice was calculated 1,3 , and $5 \mathrm{~h}$ after inflammation. The levels of superoxide dismutase (SOD), glutathione peroxidase (GSH-Px), malondialdehyde (MDA), and prostaglandin E2 (PGE2) were determined by enzyme-linked immunosorbent assay (ELISA), and the relative expression levels of cyclooxygenase-1 (COX-1) and COX-2 were determined by reverse transcription polymerase chain reaction (RT-PCR) and Western blot. Two hours after the last spraying treatment, the ulcer area of mice was measured. Tumor necrosis factor $\alpha$ (TNF- $\alpha)$, interleukin- 6 (IL-6), epidermal growth factor (EGF), and epidermal growth factor receptor (EGFR) were detected by ELISA. The degree of oral mucosal injury was observed by hematoxylin and eosin (HE) staining.

Results: Compared with positive control group, the Tr value of Yangyin Shengji powder group was lower at 30 and $60 \mathrm{~min}$, and the $\operatorname{Tr}$ value was higher at $120 \mathrm{~min}$. Yangyin Shengji powder decreased the swelling degree of toes 1,3 , and $5 \mathrm{~h}$ after inflammation, and the SOD and GSH-Px levels in the swelling tissue of toes were significantly increased. The MDA, PGE2, COX-1 and COX-2 levels were significantly decreased. The oral mucosa structure of mice in the Yangyin Shengji powder group was relatively intact and a few inflammatory cells were infiltrated. Compared with normal group, the levels of TNF- $\alpha$ and IL- 6 in the model group were increased, while the levels of EGF and EGFR were decreased $(\mathrm{P}<0.01)$. Compared with the model group, ulcer area, TNF- $\alpha$, and IL-6 levels were decreased in the Yangyin Shengji powder group, while EGF and EGFR levels were increased $(\mathrm{P}<0.01)$.

Conclusions: Yangyin Shengji powder has anti-inflammatory and analgesic effects, is anti-oxidative stress, inhibits inflammatory response, and inhibits the COX-2/PGE2 signaling pathway, so as to alleviate local inflammation of oral ulcer in mice after chemotherapy and promote wound healing.

Keywords: Yangyin Shengji powder; cyclooxygenase-2/prostaglandin E2 signaling pathway (COX-2/PGE2 signaling pathway); oral ulcer; oxidative stress

Submitted Nov 02, 2021. Accepted for publication Dec 10, 2021.

doi: $10.21037 /$ apm-21-3496

View this article at: https://dx.doi.org/10.21037/apm-21-3496 


\section{Introduction}

Oral ulcer is a kind of ulcerative injury disease that commonly occurs in the lip mucosa, buccal mucosa, and soft palate, and is typically round or oval in shape. The tissue around ulcer is often accompanied by hyperemia and edema, which seriously affects patients' daily activities such as eating and swallowing, and has an unpleasant impact on the life of those affected (1). Chemotherapy drugs, such as methotrexate, 5-fluorouracil, 6-mercaptopurine, and other metabolic drugs, often cause oral inflammation, resulting in oral ulcer (2). Methotrexate is a dihydrofolic acid reductase inhibitor, which mainly obstructs the reduction of dihydrofolic acid to tetrahydrofolic acid, resulting in blocked synthesis of DNA, RNA, and protein, and causing oral ulcers (3). Cyclooxygenase-2 (COX-2) could induce the expression of prostaglandin E2 (PGE2) to aggravate tissue inflammation via promoting the level of various inflammatory factors, like interleukins and tumor necrosis factor $\alpha(\mathrm{TNF}-\alpha)$ (4). PGE2 is the inducer of interleukins. PGE2 and these inflammatory factors could contribute to the occurrence of ulcerative colitis (5).

In the concept of Traditional Chinese medicine, the etiology of oral ulcer is spleen and stomach damp heat, Yin deficiency and Fire. Thus, a clear heat and resolve dampness and Yangyin Shengji therapy is applicative. In previous Chinese study, this therapy has been applied to treat recurrent oral ulcer (6). However, we have developed an effective drug, named Yangyin Shengji powder. One gram of Yangyin Shengji powder is consisted of $0.025 \mathrm{~g}$ realgar, $0.3 \mathrm{~g}$ calcined gypsum, $0.15 \mathrm{~g}$ indigo naturalis, $0.05 \mathrm{~g}$ mint, $0.075 \mathrm{~g}$ cortex phellodenri, $0.1 \mathrm{~g}$ pollen typhae, $0.05 \mathrm{~g}$ polygonatum, $0.1 \mathrm{~g}$ liquorice and $0.15 \mathrm{~g}$ borneol. Yangyin Shengji powder could reduce fire to consolidate Yin and promote the blood circulation by removing blood stasis. Realgar, calcined gypsum, indigo naturalis, mint, cortex phellodendri, polygonatum, liquorice and borneol can reduce fire to consolidate Yin. Pollen typhae can could promote the blood circulation by removing blood stasis. It is one of the first Traditional Chinese Medicine (TCM) Inheriting Academic Schools formulae of the State Administration of TCM, and it is an ancestral secret recipe of the Huang Clan Laryngology School of Jiangsu's intangible cultural heritage for the treatment of oral ulcer. It has been used for more than 270 years (7). In 1956, Mianqun Huang, the eighthgeneration successor of Huang Clan Laryngology, was rewarded by the Ministry of Health for his contribution of this recipe. It is now made by the Huang Clan Laryngology School of Wuxi Hospital Affiliated to Nanjing University of Chinese Medicine. It has been clinically used to treat oral ulcer after chemotherapy with good efficacy (8). This study shows first time that Yangyin Shengji powder has anti-inflammatory, analgesic, and oxidative stress-reducing effects and influences the COX2/PGE2 signaling pathway. Methotrexate was used to investigate the improvement of oral ulcer caused by this chemotherapy drug. We present the following article in accordance with the ARRIVE reporting checklist (available at https://dx.doi.org/10.21037/apm-21-3496).

\section{Methods}

\section{Experimental animals}

A total of 136 healthy and clean Institute of Cancer Research (ICR) mice aged 8 weeks (91 females and 45 males), weighing 18-25 g, 10 mice/cage, were purchased from the Experimental Animal Center of Yangzhou University. The indoor temperature was set at $22-25{ }^{\circ} \mathrm{C}$ and humidity was set at $55-65 \%$. The experiment was conducted after 1 week of adaptive feeding. The mice were fed freely, and male and female mice were raised separately in cages before and after administration. Experiments were performed under a project license (No. SWJW2021091403) granted by institutional ethics committee of Wuxi Hospital Affiliated to Nanjing University of Chinese Medicine, in compliance with Animal Care and Use Committee of Wuxi Hospital Affiliated to Nanjing University of Chinese Medicine guidelines for the care and use of animals.

\section{Reagents}

Yangyin Shengji powder is an external blowing medicine handed down from the academic school of Huang Clan Laryngology. The main ingredients are realgar (Xiong Huang), calcined gypsum (Shi Gao), indigo naturalis (Qing Dai), pollen typhae (Pu Huang), cortex phellodendri (Huang Bai), mint (Bo He), polygonatum (Huang Jing), liquorice (Gan Cao), and borneol (Bing Pian). It was provided by the Laryngology Department of Wuxi Hospital Affiliated to Nanjing University of Chinese Medicine. After crushing and mixing each medicine and grinding them into powder that can pass through a 120 -mesh sieve, and sodium carboxymethyl cellulose (CMC) was added according to the concentration to create an ointment for external 
application. The following material were procured from their respective manufacturers: CMC (S14016, Yuanye Bio, Shanghai, China), lidocaine spray (SFDA approval number H20031189, Xiangxue Pharmaceutical Co., Ltd., Guangzhou, China), dexamethasone acetate cream is $0.5 \%$ dexamethasone (Wuhu Sanyi Pharmaceutical Co., Ltd., Anhui, China), carrageenin (K02020, Hefei BASF Biological Co., Ltd., Anhui, China), methotrexate tablets (Shanghai Xinyi Pharmaceutical Co., Ltd., Shanghai, China). Superoxide dismutase (SOD), glutathione peroxidase (GSHPx), malondialdehyde (MDA) kits, TNF- $\alpha$ and interleukin-6 (IL-6) were bought from Jiancheng Institute of Biology (Nanjing, China). PGE2 were bought from Elabscience Biotechnology Co., Ltd. (Hubei, China). Epidermal growth factor (EGF) and epidermal growth factor receptor (EGFR) kits were brought from Shanghai Guangrui Biological Technology Co., Ltd. (Shanghai, China). Cyclooxygenase (COX-1) was obtained from Proteintech (Rosemont, IL, USA), COX-2 antibody was purchased from Abcam (Cambridge, MA, USA).

\section{Instrument}

The following instruments were used in our experiments: AUX220 electronic analytical balance (Shimadzu, Kyoto, Japan); intelligent hot plate meter (37370-001 UGO BASILE S.R.L., Varese, Italy); toe volume gauge (Sichuan Keyicheng, China), chemiluminescence apparatus, electrophoresis apparatus, luminescent film converter (BioRad, Hercules, CA, USA); microplate reader (Molecular Devices, San Jose, CA, USA); and Eppendorf instrument, paraffin slicing machine, optical microscope, and so on, were provided by the Department of Pathology, Wuxi Hospital Affiliated to Nanjing University of Chinese Medicine.

\section{Experimental method}

\section{Hot plate analgesic experiment Grouping}

We selected 46 female ICR mice weighing 18-22 $\mathrm{g}$ for the experiment. The scrotum of male mice exposed to heat relaxes and touches the hot plate. The testes are extremely sensitive to heat, so using male rats would affect the results. Licking the hind foot or jumping pain was the response indicator. Mice who exhibited feet licking or jumping after less than $5 \mathrm{~s}$ and more than $30 \mathrm{~s}$ were removed. The remaining 40 qualified mice were randomly divided into 4 groups with 10 mice in each group, including the blank control group, positive control group (lidocaine spray), Huang Clan Laryngology group, and excipients group (sodium CMC).

\section{Drug administration}

Before the experiment, mice were fasted for $12 \mathrm{~h}$ with free access to drinking water. The blank control group was not given the drug. The abdominal hair of mice was about shaved in ana area about $1 \mathrm{~cm}^{2}$. In the CMC sodium group and Yangyin Shengji powder group, the drugs were drawn into a microsyringe and applied to the depilated area of the abdomen and 4 paws of mice. Mice in the positive control group were sprayed with lidocaine spray in the depilated area of abdomen and 4 paws (9). The dose was about $0.05 \mathrm{~g} / \mathrm{cm}^{2}$, administered twice at an interval of $30 \mathrm{~min}$.

\section{Quality-determination method}

The room temperature was controlled at about $18{ }^{\circ} \mathrm{C}$ and the hot plate pain meter was used to cause pain, with the hot plate temperature accurately adjusted at about $55^{\circ} \mathrm{C}$. The pain threshold value was measured as the time after mice began licking their feet. The pain threshold (S) was measured twice before administration, and its mean value was taken as the normal pain threshold. The pain threshold was measured at 30,60, and $120 \mathrm{~min}$ after the second administration. If there was no response within $60 \mathrm{~s}, 60 \mathrm{~s}$ was used as the pain threshold of mice (9). The changes of pain threshold before and after administration were compared among all groups.

\section{Toe swelling experiment in mice Grouping}

We randomly divided 60 ICR mice (half male and half female) into 6 groups with 10 mice in each group, including a blank control group, model control group, positive control group (dexamethasone acetate cream), and Yangyin Shengji powder $(0.68,0.34,0.17 \mathrm{~g} / \mathrm{kg})$ groups.

\section{Drug administration}

Before the experiment, the back hair of the mice was shaven and the mice were given the drug transdermally. The volume of the drug was $0.02 \mathrm{~mL} / 10 \mathrm{~g}$, and the drug was given continuously for 5 days. At $60 \mathrm{~min}$ after the last administration, mice in the blank control group were injected subcutaneously with $20 \mu \mathrm{L}$ normal saline in the plantar pad, and mice in other groups were injected subcutaneously with $20 \mu \mathrm{L} 1 \%$ carrageenan normal saline solution in the plantar pad to induce inflammation (10).

\section{Toe swelling degree measurement}

The toe volume of mice was measured $60 \mathrm{~min}$ after the last administration, and again at 1,3 , and $5 \mathrm{~h}$ after subcutaneous 
Table 1 Primer sequences

\begin{tabular}{ll}
\hline Gene & Primer sequence \\
\hline COX-2-mouse & F: GGGAAGCCTTCTCCAACC \\
& R: GAACCCAGGTCCTCGCTT \\
COX-1-mouse & F: GGCATTGCACATCCATCCAC \\
& R: GCGCATGAGTACTTCTCGGA \\
Mouse $\beta$-actin & F: GTCCCTCACCCTCCCAAAAG \\
& R: GCTGCCTCAACACCTCAACCC
\end{tabular}

injection. Calculation of mouse toe swelling degree was as follows: toe swelling degree $=$ measured volume of mouse toe - basic volume of mouse toe (10).

Enzyme-linked immunosorbent assay (ELISA) detection of SOD, GSH-Px, MDA, and PGE2 in mucosal tissue

The ELISA was conducted as follows: a total of 10 mice in each of the blank control group, model control group, and $0.68 \mathrm{~g}$ Yangyin Shengji powder group described in the "Grouping" section were sacrificed $5 \mathrm{~h}$ after inflammation. The swollen tissue of toes was homogenized, centrifuged, and supernatant was taken. The reaction plate coated with antibody was divided into a blank well, standard well and sample well. The standard product was diluted to the required concentration according to the manufacturer's instructions. A $50 \mu \mathrm{L}$ sample was added to each standard well, $40 \mu \mathrm{L}$ of dilutant was added to each sample well and $10 \mu \mathrm{L}$ of sample solution was added. After incubation and washing, horseradish peroxidase (HRP)-labeled streptavidin $50 \mu \mathrm{L}$ was added. After incubation and washing, $50 \mu \mathrm{L}$ of color substrate tetramethylbenzidine was added. After incubation and washing, the absorbance (A) value was measured at $450 \mathrm{~nm}$ wavelength, and the standard curve was drawn according to the standard substance A value to calculate the sample concentration (10).

Quantitative reverse transcription polymerase chain reaction detection of the expression of $\mathrm{COX}-1$ and $\mathrm{COX}-2$ $m R N A$ in mucosal tissue

About $40 \mathrm{mg}$ of swelling tissue from the toes of mice in the experiment described in the "Grouping" section was taken from each group, which was cut into pieces with tissue scissors and placed in a homogenizer to collect cells from the 3 groups mentioned above. We added $1 \mathrm{~mL}$ Trizol reagent to extract total RNA from tissues. Then, $5 \mathrm{mg}$ of total RNA was taken and placed in a ribozymefree centrifuge tube, and the RNA was reverse-transcribed into complementary DNA (cDNA) according to the reverse transcription kit. Using cDNA as template, COX1 and COX-2 primers, Taq enzyme, and SYBR fluorescent dye were added to perform quantitative polymerase chain reaction (qPCR). The reaction conditions were as follows: initial denaturation $95^{\circ} \mathrm{C}$ for $30 \mathrm{~s}$, denaturation at $95^{\circ} \mathrm{C}$ for $20 \mathrm{~s}$, annealing at $55^{\circ} \mathrm{C}$ for $20 \mathrm{~s}$, and extension at $72{ }^{\circ} \mathrm{C}$ for $20 \mathrm{~s}$, for a total of 40 cycles. The $2^{-\Delta \Delta C t}$ method was used to calculate mRNA relative expression levels, and the primer sequences are shown in Table 1.

Western blot detection of the protein expression of COX-1 and COX-2 in mucosal tissue

The swelling tissue of the mice toes comprised about $80 \mathrm{mg}$ of mucosal tissue and was ground in liquid nitrogen. Lysis solution was added and centrifuged at 12,000 r/min at $4{ }^{\circ} \mathrm{C}$ for $10 \mathrm{~min}$ with a centrifugal radius of $10 \mathrm{~cm}$. Protein concentration was determined by bicinchoninic acid (BCA) method, boiled, and subjected to sample loading, $120 \mathrm{~V}$ electrophoresis for $2 \mathrm{~h}, 0.3 \mathrm{~A}$ wet transfer for $2 \mathrm{~h}$, transmembrane with polyvinylidene fluoride (PVDF) membrane, tris-buffered saline with Tween 20 (TBST) membrane washing, blocked for $1 \mathrm{~h}$, incubated with COX-1, COX-2, and $\beta$-actin primary antibody at $4{ }^{\circ} \mathrm{C}$ overnight. The membranes were washed with TBST, followed by secondary antibody incubation for $2 \mathrm{~h}$, then they were washed again with TBST, subjected to electrochemiluminescence (ECL) color rendering, and Image J (https://imagej.nih.gov/ij/) analysis of blot gray value. The gray value of the target protein blot/ $\beta$-actin gray value was the relative expression level of target protein (11).

Experimental study on wound repair of oral ulcer after chemotherapy

\section{Molding and grouping}

We selected 60 ICR mice (half male and half female, weighing 18-25 g) of which 30 mice were randomly divided into a normal group, model group, and Yangyin Shengji powder group with 10 mice in each group. Except for the normal group, mice in other groups were intraperitoneally injected with $0.8 \mathrm{mg} / \mathrm{mL}$ methotrexate at a dose of $20 \mathrm{mg} / \mathrm{kg}$. The oral cavity was observed on the second day, and oral mucosa edema, mucosal epithelial shedding, and secretions appearing on the surface were considered as successful establishment of an oral ulcer model. On the second day after modeling, mice in the Yangyin Shengji powder group were sprayed with $2 \mathrm{mg}$ Yangyin Shengji powder at the ulcer site (one spray is about $1 \mathrm{mg}$ powder), twice a day, with an interval of $5 \mathrm{~h}$ for 4 consecutive days. The normal group and model 
group were sprayed with normal saline.

\section{Oral ulcer area determination}

At $2 \mathrm{~h}$ after the last spraying, the mice in each group were sacrificed. Mucosal tissues were collected from oral ulcers, the maximum transverse diameter ( $\mathrm{d} 1$ ) and maximum longitudinal diameter (d2) of oral ulcers were measured with vernier calipers, and the sum of ulcer area was calculated. The ulcer area was calculated with the following formula: ulcer area $=\mathrm{d} 1 \times \mathrm{d} 2 \times \pi \times 1 / 4, \pi=3.14$ (12).

ELISA detection of the expression of TNF- $\alpha, I L-6, E G F$, and EGFR in mucosal tissue

Mucosal ulcer tissue of ulcer was homogenized, centrifuged, and the supernatant was taken. The reaction plate, which was coated with antibody, was divided into blank well, standard well, and sample well to be tested. The standard sample was diluted to the desired concentration according to the instructions. We then added $50 \mu \mathrm{L}$ of standard sample to each standard well, $40 \mu \mathrm{L}$ of dilutant was added to the test well, followed by $10 \mu \mathrm{L}$ of sample solution.

After incubation and washing, $50 \mu \mathrm{L}$ HRP-labeled streptavidin was added. After subsequent incubation and washing, $50 \mu \mathrm{L}$ of color substrate tetramethylbenzidine was added. Then, after incubation and washing, the A value was measured at $450 \mathrm{~nm}$ wavelength, and the standard curve was drawn according to the standard substance A value to calculate the sample concentration (13).

\section{Hematoxylin and eosin (HE) staining detection of the pathological changes of mucosa}

The mucosa tissue was taken, fixed in $4 \%$ paraformaldehyde, dehydrated, embedded, sliced ( $4 \mu \mathrm{m}$ thick), stained with HE, sealed with neutral resins, observed under a microscope, and photographed.

\section{Statistical analysis}

The statistical software SPSS 21.0 (IBM Corp., Armonk, NY, USA) was used to analyze the data, and all measurement data were described as mean \pm standard deviation $(\mathrm{SD})$. One-way analysis of variance (ANOVA) was used for comparison of various measurement data, and the least significant difference (LSD) $t$-test was used for comparison of pairs of samples. A P value $<0.05$ was considered statistically significant.

\section{Results}

\section{Analgesic results}

There was no significant difference among the groups in pain threshold before administration $(\mathrm{P}>0.05)$. Compared with the blank control group, there was no difference in pain threshold of the excipient group (sodium CMC) 30, 60, and $120 \mathrm{~min}$ after administration. The pain threshold of the positive control group (lidocaine spray) and Yangyin Shengji powder group increased 30, 60, and $120 \mathrm{~min}$ after administration $(\mathrm{P}<0.01)$. The pain threshold of mice in the positive control group increased 30 and 60 min after administration, which was higher than the Yangyin Shengii powder group, and at $30 \mathrm{~min}$ after adminstration there was statistical significance $(\mathrm{P}<0.01)$. At $120 \mathrm{~min}$ after administration, the pain threshold of mice in the Yangyin Shengji powder group was higher than that in the positive control group, and the result was no significant difference $(\mathrm{P}>0.05)$ (Table 2).

\section{Results of anti-inflammatory and mechanism experiments}

\section{Results of toe swelling experiment in mice}

Before modeling, there was no significant difference in basal foot volume among all groups $(\mathrm{P}>0.05)$. After modeling, compared with the blank control group, the swelling degree of toes in the model control group increased significantly at 1,3 , and $5 \mathrm{~h}$ after inflammation $(\mathrm{P}<0.01)$. Compared with the model control group, the toe swelling degree of positive control group and Yangyin Shengji powder high, medium, and low concentration groups was decreased at 1,3 , and $5 \mathrm{~h}$ after inflammation. At 1 and $3 \mathrm{~h}$ after inflammation, the foot swelling degree in positive control group, Yangyin Shengji powder high, medium, and low concentration groups was significantly reduced $(\mathrm{P}<0.01)$. At $5 \mathrm{~h}$ after inflammation, the swelling degree of toes in the positive control group and Yangyin Shengji powder high and medium concentration groups were significantly decreased $(\mathrm{P}<0.01)$, and that in the low concentration group was significantly decreased $(\mathrm{P}<0.05)$ (Table 3).

\section{ELISA detection results}

Compared with the blank control group, the SOD and GSHPx levels in mice swelling toes tissue in model group were significantly decreased $(\mathrm{P}<0.01)$, while the MDA and PGE2 levels were significantly increased $(\mathrm{P}<0.01)$. Compared with model group, the levels of SOD and GSH-Px in the swollen toes tissue of mice in the Yangyin Shengji powder group were significantly increased $(\mathrm{P}<0.01)$, while MDA and PGE2 were significantly decreased $(\mathrm{P}<0.01)$ (Figures $1-4)$.

\section{qRT-PCR detection results}

Compared with blank group, the mRNA expression levels 
Table 2 Measurement results of hot plate pain threshold of mice in each group $(\mathrm{n}=10)$

\begin{tabular}{|c|c|c|c|c|c|c|c|}
\hline Group & $\begin{array}{c}\text { Tr before } \\
\text { administration }\end{array}$ & \multicolumn{2}{|c|}{$30 \mathrm{~min}$} & \multicolumn{2}{|c|}{$60 \mathrm{~min}$} & \multicolumn{2}{|c|}{$120 \min$} \\
\hline Blank group & $12.44 \pm 4.20$ & $13.63 \pm 5.12$ & 9.57 & $15.30 \pm 3.81$ & 22.99 & $16.42 \pm 4.35$ & 31.99 \\
\hline $\begin{array}{l}\text { Excipients } \\
\text { group }\end{array}$ & $14.93 \pm 4.97$ & $16.92 \pm 5.72$ & 13.33 & $14.60 \pm 4.02$ & -2.18 & $16.34 \pm 6.56$ & 9.49 \\
\hline $\begin{array}{l}\text { Yangyin Shengji } \\
\text { powder group }\end{array}$ & $15.30 \pm 4.01$ & $29.44 \pm 9.97^{\star \star}$ & 92.42 & $34.86 \pm 11.14^{\star \star}$ & 127.84 & $38.95 \pm 11.23^{\star \star}$ & 154.58 \\
\hline $\begin{array}{l}\text { Positive control } \\
\text { group }\end{array}$ & $15.92 \pm 4.78$ & $42.76 \pm 10.63^{\star \star}$ & 168.59 & $41.43 \pm 10.11^{* *}$ & 160.24 & $34.92 \pm 10.64^{\star *}$ & 119.36 \\
\hline
\end{tabular}

Data are expressed as mean \pm standard deviation. ${ }^{* \star}$, compared with blank group, $\mathrm{P}<0.01$. Tr, threshold of pain reflex.

Table 3 Measurement results of hot plate pain threshold of mice in each group $(n=10)$

\begin{tabular}{|c|c|c|c|c|}
\hline Group & $\begin{array}{l}\text { Toe volume } \\
\text { baseline }(\mu \mathrm{L})\end{array}$ & \multicolumn{3}{|c|}{ Degree of swelling of toes } \\
\hline Model control group & $262.60 \pm 27.76$ & $36.20 \pm 8.36^{\star \star}$ & $48.70 \pm 8.06^{\star \star}$ & $28.40 \pm 8.26^{\star \star}$ \\
\hline Yangyin Shengji powder medium group & $260.60 \pm 25.34$ & $22.10 \pm 4.15^{\# \#}$ & $29.70 \pm 5.72^{\# \#}$ & $16.10 \pm 4.51^{\# \#}$ \\
\hline Yangyin Shengji powder low group & $243.80 \pm 29.95$ & $25.50 \pm 3.84^{\# \#}$ & $30.30 \pm 5.37^{\# \#}$ & $21.00 \pm 6.48^{\#}$ \\
\hline
\end{tabular}

Data are expressed as mean \pm standard deviation. ${ }^{* *}$, compared with the blank control group, $\mathrm{P}<0.01$. Compared with the model control group, ", $\mathrm{P}<0.05$; \#, $\mathrm{P}<0.01$.

of COX-1 and COX-2 in swollen toe tissues of mice in the model control group were increased $(\mathrm{P}<0.01)$. Compared with the model control group, the expression levels of COX-1 mRNA and COX-2 mRNA in the swollen toe tissue of mice in the Yangyin Shengji powder group were decreased $(\mathrm{P}<0.01)$ (Figures 5,6).

\section{Western blot detection results}

Compared with the blank group, COX-1 and COX2 protein expression levels in the swollen toe tissues of mice in the model control group were increased $(\mathrm{P}<0.01)$; Compared with the model control group, the expression levels of COX-1 and COX-2 proteins in the swelling tissues of mice in the Yangyin Shengji powder group were decreased $(\mathrm{P}<0.01)$ (Figure 7).

\section{Oral ulcer healing experiment after chemotherapy}

\section{Oral ulcer area measurement results}

There was a statistically significant difference in oral ulcer area between groups $(\mathrm{P}<0.01)$. Compared with the model group, the area of oral ulcer in the Yangyin Shengji powder group was decreased (Table 4).

\section{ELISA assay detection results}

Compared with normal group, the levels of TNF- $\alpha$ and IL-6 in mucosal tissues of the model group were increased, while the levels of EGF and EGFR were decreased $(\mathrm{P}<0.01)$. Compared with model group, the levels of TNF- $\alpha$ and IL-6 in mucosal tissues of mice in the Yangyin Shengji powder group were decreased, while the levels of EGF and EGFR were increased $(\mathrm{P}<0.01)$ (Table 5). 


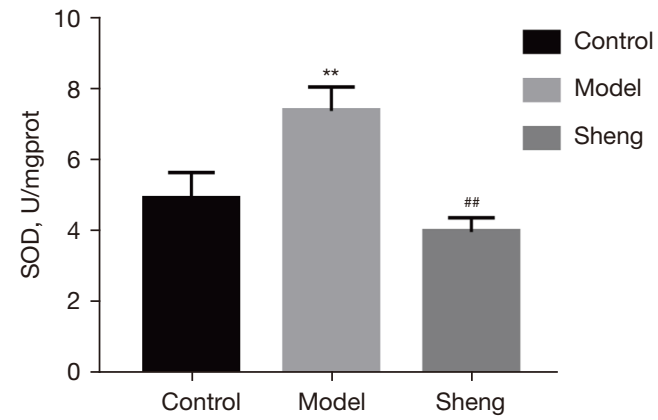

Figure 1 Comparison of SOD level in swollen toe tissues of the 3 groups. **, compared with blank control group, $\mathrm{P}<0.01$; ${ }^{* \#}$, compared with the model control group, $\mathrm{P}<0.01$. SOD, superoxide dismutase.

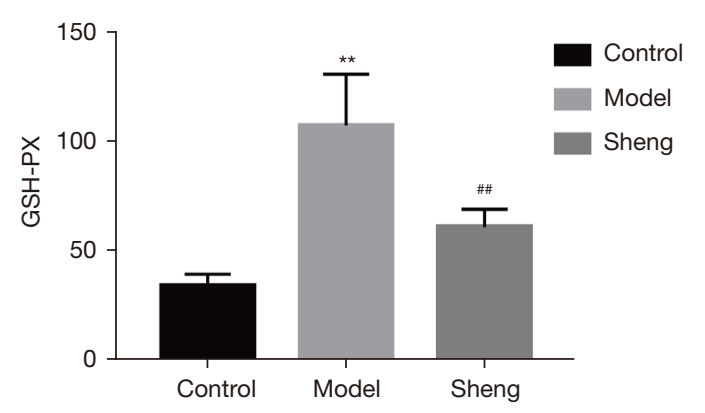

Figure 2 Comparison of GSH-Px level in swollen toe tissues of the 3 groups. ${ }^{* *}$, compared with blank control group, $\mathrm{P}<0.01$; \#, compared with the model control group, $\mathrm{P}<0.01$. GSH-Px, glutathione peroxidase.

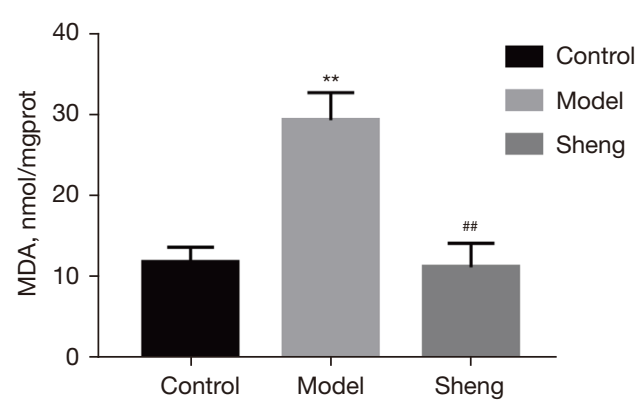

Figure 3 Comparison of MDA level in swollen toe tissues of the 3 groups. **, compared with blank control group, $\mathrm{P}<0.01$; \#, compared with the model control group, $\mathrm{P}<0.01$. MDA, malondialdehyde.

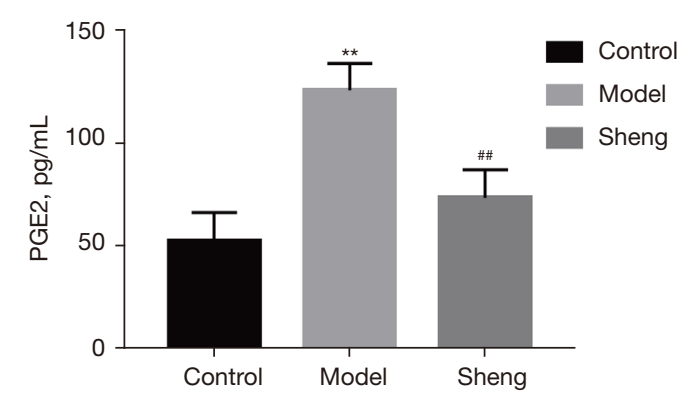

Figure 4 Comparison of PGE2 level in swollen toe tissues of the 3 groups. ${ }^{* *}$, compared with blank control group, $\mathrm{P}<0.01$; \#\#, compared with the model control group, $\mathrm{P}<0.01$. PGE2, prostaglandin E2.

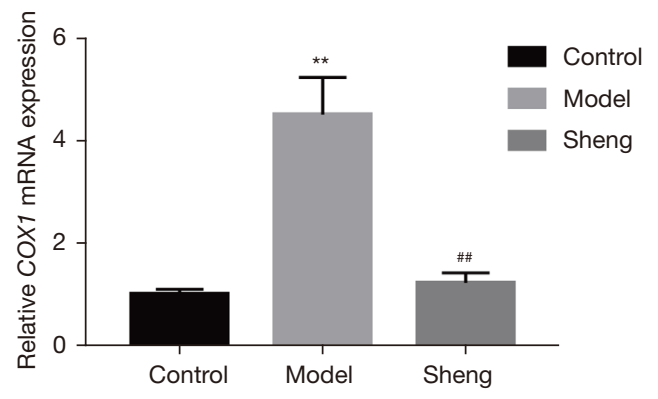

Figure 5 Comparison of COX-1 mRNA expression in swollen toe tissues of the 3 groups. **, compared with blank control group, $\mathrm{P}<0.01 ;$; , compared with the model control group, $\mathrm{P}<0.01$. COX1 , cyclooxygenase- 1 .

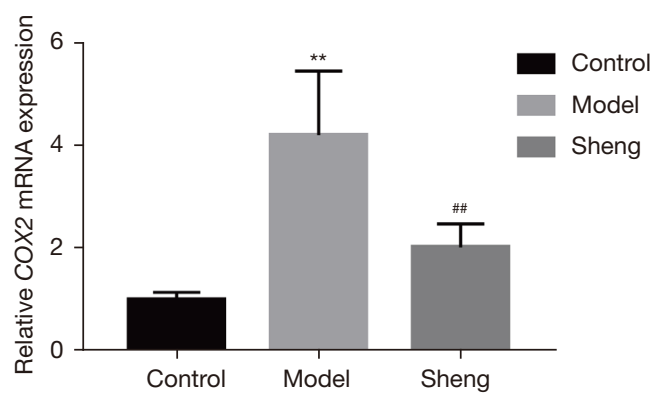

Figure 6 Comparison of COX-2 mRNA expression in swollen toe tissues of the 3 groups. **, compared with blank control group, $\mathrm{P}<0.01 ;{ }^{\# \#}$, compared with the model control group, $\mathrm{P}<0.01$. COX2, cyclooxygenase-2. 

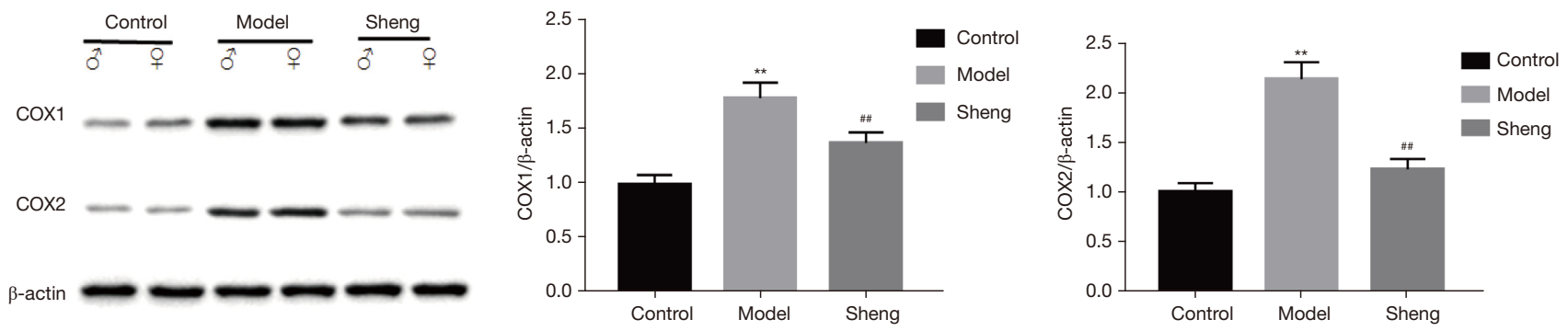

Figure 7 Comparison of COX-1 and COX-2 protein expression in swollen toe tissues of the 3 groups. ${ }^{* *}$, compared with blank control group, $\mathrm{P}<0.01$; ${ }^{\prime \prime}$, compared with the model control group, $\mathrm{P}<0.01$. COX-1, cyclooxygenase-1. COX-2, cyclooxygenase-2.

Table 4 Comparison of oral ulcer area between the two groups $(\mathrm{n}=10)$

\begin{tabular}{lc}
\hline Group & Ulcer area $\left(\mathrm{mm}^{2}\right)$ \\
\hline Model group & $5.20 \pm 0.36$ \\
Yangyin Shengji powder group & $3.28 \pm 0.29^{\# \#}$ \\
$t$ & 13.17 \\
$P$ value & $<0.001$ \\
\hline
\end{tabular}

Data are expressed as mean \pm standard deviation. ${ }^{\# \#}$, compared with the model group, $\mathrm{P}<0.01$.

\section{Pathological injury of mucosal tissue}

The oral mucosa of mice in the normal group was covered with squamous epithelium with intact tissue structure and infiltration of focal inflammatory cells. In the model group, oral mucosa tissue structure was damaged, squamous epithelium was exfoliated, a large number of inflammatory cells were infiltrated, and capillaries were dilated. The oral mucosa structure of mice in the Yangyin Shengji powder group was relatively intact and a few inflammatory cells were infiltrated (Figure 8).

\section{Discussion}

Yangyin Shengji powder is composed of realgar, calcined gypsum, indigo naturalis, pollen typhae, cortex phellodendri, mint, polygonatum, liquorice and borneol (8). Modern pharmacological studies have found that realgar and indigo naturalis have antibacterial and antiviral effects, calcined gypsum can enhance the phagocytosis of macrophages, cortex phellodendri and liquorice have antibacterial, antiinflammatory, anti-ulcer, and immunological function regulation role, polygonatum can adjust the balance of immune function, and borneol has anti-inflammatory and analgesic effects (14).
Studies have shown that Yangyin Shengji powder can improve oral ulcer in rats, but the specific mechanism has remained unclear (15). Therefore, the pharmacodynamics of Yangyin Shengji powder was studied in this study, and the therapeutic effect of Yangyin Shengji powder on oral ulcer induced by methotrexate was discussed.

It is common for inflammation and pain to co-present. Oral ulcers produce severe pain due to local inflammatory reactions, which affects eating. Inflammatory reactions can interfere with the metabolism of free radicals in tissues and organs and promote the excessive formation of free radicals, leading to oxidative stress reaction and tissue cell damage (10). The degree of tissue damage can be reflected by MDA, as it is the oxidation end product formed by the action of free radicals. Both SOD and GSH-Px are important antioxidant substances in organisms, and their changes can reflect the antioxidant capacity of body tissues (16). Under the stimulation of various inflammatory and pain-causing factors, the level and activity of SOD and GSH-Px are reduced, resulting in mitochondrial dysfunction, lysosome and lipid membrane destruction, aggravated tissue and organ damage, and further aggravated and amplified inflammation and pain response (17). As a pro-inflammatory factor, PGE2 can cause local vascular dilation, enhance microvascular permeability, recruit neutrophils, and promote the synthesis of COX-2, mediate the production and release of a series of inflammatory factors such as TNF- $\alpha$ and IL6 , and enhance the intensity and duration of inflammatory response (18). The COX enzyme is pivotal in arachidonic acid synthesis (PGs), and there are 2 isoenzymes of different subtypes, COX-1 and COX-2 (19). Studies have found that Erythrina speciosa (Fabaceae) leaves can reduce inflammatory response in ethanol-induced gastric ulcer rats, reduce oxidative stress level, inhibit COX-2 and PGE2 expression, thereby alleviating ulcerative injury 
Table 5 Comparison of TNF- $\alpha$, IL-6, EGF, and EGFR in mucosal tissues of mice in the three groups (n=10)

\begin{tabular}{lcccc}
\hline Group & TNF- $\alpha(\mathrm{ng} / \mathrm{mL})$ & $\mathrm{IL}-6(\mathrm{ng} / \mathrm{mL})$ & EGF $(\mathrm{ng} / \mathrm{L})$ & $\mathrm{EGFR}(\mu \mathrm{g} / \mathrm{L})$ \\
\hline Normal group & $94.50 \pm 10.82$ & $27.46 \pm 5.32$ & $370.63 \pm 14.36$ & $3.59 \pm 0.14$ \\
Model group & $267.52 \pm 15.69^{\star \star}$ & $89.37 \pm 9.58^{\star *}$ & $240.66 \pm 2.31^{\star \star}$ & $2.46 \pm 0.24^{\star \star}$ \\
Yangyin Shengji powder group & $177.05 \pm 11.47^{\star \star \# \#}$ & $61.32 \pm 8.40^{\star \star \# \#}$ & $319.75 \pm 6.93^{\star \star \# \#}$ & $2.95 \pm 0.11^{\star \star \# \#}$ \\
\hline
\end{tabular}

${ }^{\star *}$, compared with blank group, $\mathrm{P}<0.01$; \#\#, compared with model group, $\mathrm{P}<0.01$. TNF- $\alpha$, tumor necrosis factor $\alpha$; IL-6, interleukin-6; EGF, epidermal growth factor; EGFR, epidermal growth factor receptor.
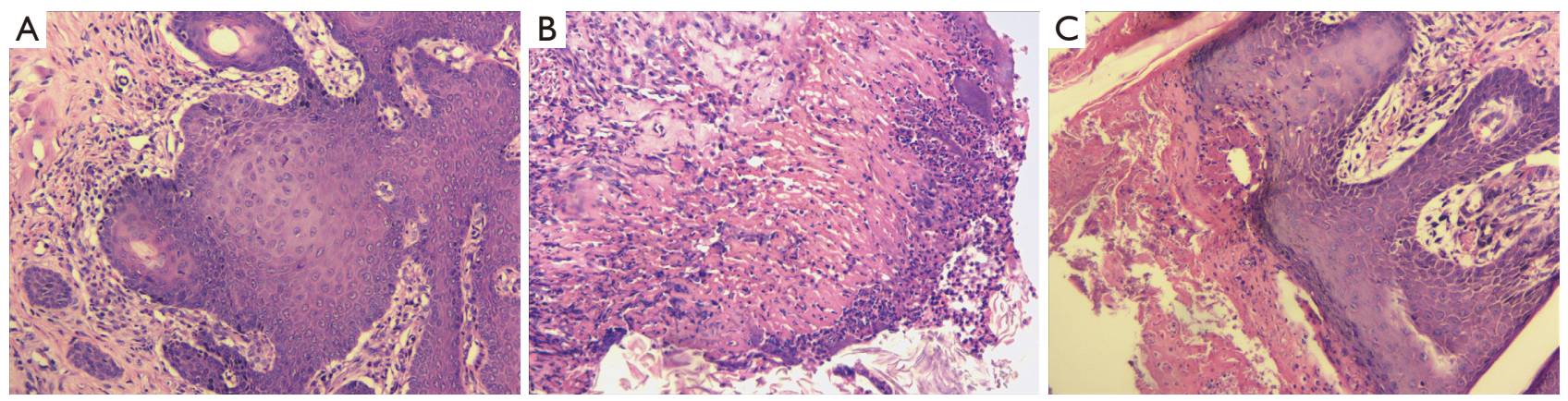

Figure 8 Hematoxylin and eosin staining of mucosal tissues (×200). (A) Normal group; (B) model group; (C) Yangyin Shengji powder group.

and promoting wound healing (20). At the same time, recent studies have suggested that COX-1 is also involved in inflammation and exacerbates inflammation, and selective inhibition of COX-1 activity can effectively treat inflammation. Therefore, COX-1 has been reconsidered as a target for inflammatory treatment $(21,22)$. In this study, analgesic experiments and toe swelling experiments showed that Yangyin Shengji powder could relieve inflammation and pain. The levels of SOD and GSH-Px in swollen mouse toe tissues were significantly increased $(\mathrm{P}<0.01)$. The MDA and PGE2 levels were significantly decreased $(\mathrm{P}<0.01)$. The mRNA and protein expression levels of COX-1 and COX-2 decreased significantly $(\mathrm{P}<0.01)$. The results showed that Yangyin Shengji powder could resist oxidative stress, inhibit the COX-2/PGE2 signaling pathway, and inhibit COX-1.

Chemotherapy drugs can directly or indirectly cause damage to oral mucosa. The direct effect is that chemotherapy drugs can inhibit the proliferation and renewal of oral mucosa epithelial cells, resulting in the epithelial cell renewal interval between new and old mucosa, thus causing ulcers. The indirect effect is that chemotherapy drugs can cause imbalance of bone marrow and immune function of the body, induce local infection and lead to mucosal damage, and oral ulcer caused by methotrexate chemotherapy is very common $(23,24)$. The occurrence of oral ulcer and immune function imbalance and abnormal activation of the inflammatory response is closely related to oxidative stress, TNF- $\alpha$, IL-6, and other inflammatory factors. This relationship plays an important role in the process of oral ulcer disease, TNF- $\alpha$ is released by mononuclear cells into the blood, damages the mucosal cells, and enhances the oral vascular endothelial cell permeability, resulting in edema of mucosa lamina propria (25). Massive release of TNF- $\alpha$ leads to secretion of various pro-inflammatory factors such as IL-6, which further aggravates oral ulcer (26). Wound healing is mainly achieved by epidermal cell division and proliferation and proliferation of fibroblasts, and a large amount of extracellular matrix is secreted at the same time. The division and proliferation of epidermal cells depends on EGF, and EGF is the main mitogen of epidermal cells. Wang et al. found that Kamistad gel could reduce the inflammatory response of experimental oral ulcer rats, promote the expression of EGF and EGFR, and have anti-inflammatory, analgesic, and healing effects on oral ulcer (27). The results of this study showed that Yangyin Shengji powder could effectively relieve pain and reduce local inflammation. After chemotherapy, the oral mucosa tissue structure of mice in the oral ulcer model group was 
damaged, the squamous epithelium was exfoliated, a large number of inflammatory cells infiltrated, and capillaries were dilated. The oral mucosa structure of mice in the Yangyin Shengji powder group was relatively intact and a few inflammatory cells were infiltrated. Compared with the normal group, the ulcer area of mice in the Yangyin Shengji powder group was decreased, the levels of TNF- $\alpha$ and IL-6 were decreased, and the levels of EGF and EGFR were increased. The results showed that Yangyin Shengji powder could reduce the inflammatory response of oral ulcer mice and promote the wound healing of ulcer. This study mainly focused on the mechanism of Yangyin Shengji powder, so no control group was set.

In conclusion, Yangyin Shengji powder has clear antiinflammatory, analgesic, and antioxidant stress effects, which can relieve chemotherapy-induced oral ulcer, reduce inflammatory response, and promote ulcer wound healing. The results of this study indicate that it exerts its effect by inhibiting the COX-2/PGE2 signaling pathway, which provides a theoretical basis for clinical treatment of oral ulcer.

\section{Acknowledgments}

Funding: This was supported by the Jiangsu Provincial Administration of Traditional Chinese Medicine (No. LB13006).

\section{Footnote}

Reporting Checklist: The authors have completed the ARRIVE reporting checklist. Available at https://dx.doi. org/10.21037/apm-21-3496

Data Sharing Statement: Available at https://dx.doi. org/10.21037/apm-21-3496

Conflicts of Interest: All authors have completed the ICMJE uniform disclosure form (available at https://dx.doi. org/10.21037/apm-21-3496). The authors have no conflicts of interest to declare.

Ethical Statement: The authors are accountable for all aspects of the work in ensuring that questions related to the accuracy or integrity of any part of the work are appropriately investigated and resolved. Experiments were performed under a project license (No. SWJW2021091403) granted by institutional ethics committee of Wuxi Hospital
Affiliated to Nanjing University of Chinese Medicine, in compliance with Animal Care and Use Committee of Wuxi Hospital Affiliated to Nanjing University of Chinese Medicine guidelines for the care and use of animals.

Open Access Statement: This is an Open Access article distributed in accordance with the Creative Commons Attribution-NonCommercial-NoDerivs 4.0 International License (CC BY-NC-ND 4.0), which permits the noncommercial replication and distribution of the article with the strict proviso that no changes or edits are made and the original work is properly cited (including links to both the formal publication through the relevant DOI and the license). See: https://creativecommons.org/licenses/by-nc-nd/4.0/.

\section{References}

1. Rioboo-Crespo Mdel R, Planells-del Pozo P, RiobooGarcía R. Epidemiology of the most common oral mucosal diseases in children. Med Oral Patol Oral Cir Bucal 2005;10:376-87.

2. Cardona A, Balouch A, Abdul MM, et al. Efficacy of chlorhexidine for the prevention and treatment of oral mucositis in cancer patients: a systematic review with meta-analyses. J Oral Pathol Med 2017;46:680-8.

3. Bertino JR. Cancer research: from folate antagonism to molecular targets. Best Pract Res Clin Haematol 2009;22:577-82.

4. Kudo I, Murakami M. Phospholipase A2 enzymes. Prostaglandins Other Lipid Mediat 2002;68-69:3-58.

5. Li Y, Soendergaard C, Bergenheim FH, et al. COX-2PGE2 Signaling Impairs Intestinal Epithelial Regeneration and Associates with TNF Inhibitor Responsiveness in Ulcerative Colitis. EBioMedicine 2018;36:497-507.

6. Wang Z, Xie J, Miao W, et al. Clinical Observation on Recurrent Oral Ulcer Treated with Therapy of Clearing Heat and Removing Dampness,Nourishing Yin and Promoting Granulation. Journal of Guangzhou University of Traditional Chinese Medicine 2019;36:640-4.

7. Ren S. Review of Wuxi Huang school of laryngeal therapy. Jiangsu Journal of Traditional Chinese Medicine 2017;49(4):70-3.

8. Ren S, Liu Y, Xu L, et al. Clinical observation of Huangshi Yangyin Shengji Powder in the treatment of oral ulcer after chemotherapy. Chinese Journal of Otorhinolaryngology in Integrative Medicine 2012;20:60.

9. Yang L, Luo Z, Peng J, et al. Study on the antaligic and anti-inflammatory actions of Blood invigorating and 
pain easing tincture. Northwest Pharmaceutical Journal 2017;32:761-3.

10. Fu C, Wang M, Xu S, et al. Effects of Analgesic and Anti-inflammatory of Sophocarpine and Related COX-2/PGE2Signaling Pathway. China Pharmacy 2019;30:1775-80.

11. Ren L, Ren X, Liu J, et al. Study on the Mechanism of Anti-inflammatory Pain Effect of Allicin in Model Mice. China Pharmacy 2018;29:2479-83.

12. Liu H, Zheng Y, Li C, et al. Protective effects of Kouyanqing Granule on the oral ulcer rat model with Yinxu-huo-wang syndrome. Acta Scientiarum Naturalium Universitatis Sunyatseni 2018;57:131-6.

13. Tang B, Yin K. Effect of JiangzhiLigan Decoction on noncanonical pyroptosis pathway in rats with high-fat dietinduced non-alcoholic fatty liver disease. Chinese Journal of Immunology 2020;36:267-71.

14. Sun X, Ou L, Mi S, et al. Analgesic and Anti-inflammation Effect of Borneol. Traditional Chinese Drug Research and Clinical Pharmacology 2007;18:353-5.

15. Liu Y, Ren S, Ji H, et al. Experimental study of Huangshi Shengji Powder on oral ulcer in rats. Chinese Journal of Otorhinolaryngology in Integrative Medicine 2019;27:84-5.

16. Zhang Y, Wang S, Hao M. Study on the antioxidant and anti-inflammatory effects of persimmon leaf flavonoids in experimental oral ulcer. Journal of Taishan Medical College 2017;38:1000-2.

17. Avci E, Akarslan ZZ, Erten H, et al. Oxidative stress and cellular immunity in patients with recurrent aphthous ulcers. Braz J Med Biol Res 2014;47:355-60.

18. Bansal M, Singh N, Alam S, et al. Alternariol induced proliferation in primary mouse keratinocytes and inflammation in mouse skin is regulated via PGE2/ EP2/cAMP/p-CREB signaling pathway. Toxicology 2019;412:79-88.

Cite this article as: Liu Y, Ren S, Ji H, Yan D. Study on the inhibition of inflammation by the cyclooxygenase-2 (COX2)/prostaglandin E2 (PGE2) pathway and the promotion of wound healing of oral ulcer of Yangyin Shengji powder after chemotherapy. Ann Palliat Med 2021;10(12):12716-12726. doi: 10.21037/apm-21-3496
19. Jafarnezhad-Ansariha F, Yekaninejad MS, Jamshidi AR, et al. The effects of $\beta$-D-mannuronic acid (M2000), as a novel NSAID, on COX1 and COX2 activities and gene expression in ankylosing spondylitis patients and the murine monocyte/macrophage, J774 cell line. Inflammopharmacology 2018;26:375-84.

20. Fahmy NM, Al-Sayed E, Michel HE, et al. Gastroprotective effects of Erythrina speciosa (Fabaceae) leaves cultivated in Egypt against ethanol-induced gastric ulcer in rats. J Ethnopharmacol 2020;248:112297.

21. Korbecki J, Baranowska-Bosiacka I, Gutowska I, et al. Cyclooxygenase- 1 as the main source of proinflammatory factors after sodium orthovanadate treatment. Biol Trace Elem Res 2015;163:103-11.

22. Kang X, Chen G, Cao W, et al. Cyclooxygenase-1 and its selective inhibitors: Research progress and perspectives. Chinese Journal of Antibiotics 2016;41:727-34.

23. Heil SG. Genetics of high-dose methotrexate-induced oral mucositis: current perspectives. Pharmacogenomics 2019;20:621-3.

24. Li X, Liu X. Observation on the Curative Effect of High-dose of Vitamin C on the Treatment for Oral Ulcers Caused by Chemotherapy. Medical Recapitulate 2015;21:1499-501.

25. Zou Y, Yang J, Chen C. Correlation of TNF- $\alpha$, IL-2,6 and immune function with recurrent oral ulcers. Journal of Hainan Medical University 2015;21:1299-301.

26. Yin S, Yan Y, Huang T, et al. Therapeutic effect of Artemisia argyi on oral ulcer in rats. Zhong Nan Da Xue Xue Bao Yi Xue Ban 2017;42:824-30.

27. Wang Y, Wu Y, Yu X, et al. Effect of Kamistad gel on oral ulcer healing and TNF- $\alpha$, IL-6 and EGF expression in ulcer tissue of rats. Journal of Prevention and Treatment For Stomatological Diseases 2019;27:293-9.

(English Language Editor: J. Jones) 